\title{
Morphometric Alteration of Intestinal Epithelium of Rats (Rattus norvegicus) Submitted to the Technique of Enteropexy
}

\author{
Genilson Fernandes de Queiroz' ${ }^{1}$ Taciana de Melo Fernandes Silva ${ }^{2}$, Kilder Dantas Filgueira ${ }^{3}$, \\ Moacir Franco de Oliveira', Hildita Simea de Andrade Chaves'2, Giovanna Carla de Oliveira Campos ${ }^{3}$, \\ Gleidson Benevides de Oliveira², Luã Barbalho de Macêdo², Muriel Magda Lustosa Pimentel'2, \\ Robério Gomes Olinda ${ }^{4} \&$ Maria Angélica Miglino ${ }^{5}$
}

\begin{abstract}
Background: Due to the numerous complications that enteropexy may cause in domestic animals and humans, this study aimed at investigating the microscopic level, the damage generated by this technique in mice, in order to investigate the morphometric changes caused by enteropexy technique in rats.

Materials, Methods \& Results: Eighteen Wistar rats were submitted to surgical technique of enteropexy. To evaluate intestinal disorders they were euthanized at 30 (Group I), 60 (group II) and 90 (group III) days after the procedure. The animals were perfused with $2.5 \%$ glutaraldehyde and $4 \%$ paraformaldehyde for the removal of intestinal fragments for analysis in conventional microscopy and scanning electron microscopy. In classical histopathology, group I presented mild lesions with necrosis of the epithelium and infiltration of mononuclear cells. After 60 days, extensive ischemic necrosis area was observed, characterized by the denudation of epithelium cells and cellular debris in the lumen surface and loss of intestinal crypts. After 90 days (group III) lesions were evident and were characterized by strong coagulative necrosis of epithelial cells and intestinal crypts. Under electron microscopy, group I showed early fusion of the adjacent intestinal walls. After 60 days there was adherence of luminal stenosis and intestinal walls. In group III loss of epithelium and substitution of necrotic tissue were identified.

Discussion: In the current study it was noticed microscopically that the groups had inflammatory reactions to foreign bodies. It is known that the sutures, independent of manufacture, behave as foreign bodies that induce tissue inflammation of the recipient organism and could harm the scar repair. Among the surgical threads, the nylon type (which was chosen for the current experiment) is indicated in the approach tissues in general and bandages, including cardiovascular, ophthalmic and neurological procedures. This category wire induces minimal inflammation of the receptor tissue. In studies of the histopathological analysis of the tissue reactions produced by the wire implant or nylon thread clamp in rats, it was observed that when the local action of two implants were compared, inflammation showed qualitatively similar responses, although they had different characteristics regarding their course. Inflammation is proportional to the proliferation of fibroblasts and the presence of fibrous tissue around the suture. This quote confirms the analyzed samples, in which, in all postoperative times showed inflammatory process, although at different magnitudes. Surgical research in laboratory animals has expanded in recent decades, mainly due to better anesthetic support, the sophistication of infrastructure, material for perioperative continuous monitoring and an incessant search for species that reproduce human morbid conditions. The main focus of these studies have been improving the knowledge about the pathophysiological mechanisms of disease, undertake therapeutic trials with new drugs, studying biomarkers and evaluate new techniques to be applied prospects in man. The most common sites of occurrence of intestinal are ileocolic intussusception junction and jejunojejunal segment. The enteroplication has been used to reduce the occurrence of intussusception, promoting the adhesion of the adjacent serosa layers of intestinal segments and thereby decreasing intestinal motility, their applicability is reported in humans, dogs and cats. The enteropexy technique causes morphological changes in intestinal epithelium of rats, evidenced in conventional and electron microscopy, progress with the passing of time the procedure.
\end{abstract}

Keywords: intestinal surgery, surgical complications, intussusception, microscopy. 


\section{INTRODUCTION}

The enteropexy is a surgical technique to prevent recurrence of intussusception both in human medicine and in veterinary medicine $[7,12]$. This procedure is used in all patients, but especially in young animals, the higher incidence of intussusception mainly due to gastroenteritis and ingestion of foreign bodies [8]. This is accomplished by suturing the adjacent loops of intestine from the duodenocolic ligament to the ileocolic junction, reducing intestinal strangulation potential [13]. The handles are attached to each other by placing sutures covering the serous, muscular and submucosa of the intestine [7].

Intestinal plication (or enteropexy), as is also defined experimentally produces significant morbidity, resulting in vomiting, diarrhea, anorexia, constipation, obstruction, adhesions, perforation and septic peritonitis, especially after a month of surgery [18]. Research with enteropexy execution in dogs observed a gradual increase of adhesions from seven to 30 days after surgery [1].

Due to the numerous complications that enteropexy may cause in domestic animals and humans, this study aimed at investigating the microscopic level, the damage generated by this technique in mice.

\section{MATERIALS AND METHODS}

\section{Animals and experimental design}

Eighteen Wistar rats were used, weighing approximately $200 \mathrm{~g}$, adults, male and female, from the vivarium of the Universidade Federal Rural do SemiÁrido (UFERSA, Mossoró, RN, Brazil). The animals were randomly divided into three groups of 6 animals given the postoperative time. Group I - 30, group II 60 and III group - 90 days after enteropexy procedure. The study was approved by the Ethics Commission on the use of animals in UFERSA, receiving the protocol number 577/2004.

The rats were anesthetized using xylazine $2 \%$ $(10 \mathrm{mg} / \mathrm{kg})$ and ketamine hydrochloride 5\% (50 mg/ $\mathrm{kg}$ ), both administered intramuscularly. They were submitted to tricotomy and antisepsis of the abdominal region with $10 \%$ polyvinylpyrrolidone-iodine solution. The specimens were positioned supine, with performing celiotomy through an incision in the midline, with a length of $2.0 \mathrm{~cm}$.
After opening the abdominal cavity, the omentum was retracted to expose the small intestine. The jejunum was identified and in an approximately $20 \mathrm{~cm}$ in length, the ntestinal loops were arranged side by side, and seromuscular coats were sutured on the antimesenteric with simple interrupted stitches, with intervals of $0.5 \mathrm{~cm}$, using a nylon yarn 4-0. When the integrity plication is observed, the handles have been replaced in the abdominal cavity. Synthesis was performed from the abdominal wall with simple interrupted suture (4-0 nylon thread), and then the skin with the same pattern of suture wire.

After the postoperative period of each group (30, 60 and 90 days), the animals were sacrificed with an anesthetic overdose of ketamine and xylazine and thereafter via intracardiac potassium chloride. After the individuals were perfused with glutaraldehyde association and paraformol $4 \%$ (10 mL/animal) inside aorta.

Fragments were collected from 2 to $4 \mathrm{~cm}$ of the intestine of mice. The samples were fixed in $4 \%$ paraformaldehyde in $0.1 \mathrm{M}$ sodium phosphate buffer and $\mathrm{pH} 7.4$ when intended for processing light microscopy, and $2.5 \%$ glutaraldehyde in $0.1 \mathrm{M}$ sodium phosphate buffer and $\mathrm{pH} 7.4$, for analysis in scanning electron microscopy.

\section{Histopathology}

For the classic histopathological processing, after attachment, the fragments were washed in running water and then subjected to dehydration processes in increasing concentrations of alcohol (70\% to $100 \%)$, diaphanized in xylol bath, immersed in histological paraffin (granulated with melting point $58^{\circ} \mathrm{C}$ to $62^{\circ} \mathrm{C}$ ), and the prepared blocks, yielding then with the aid of a microtome, 5 to $7 \mu \mathrm{m}$-thick slices, and the slides stained with hematoxilin - eosin (HE) according to the methodology already described (7). The blades were made, viewed in a light microscope (Olympus CX 31 RBSFA) and the most representative, photomicrographed.

\section{Scanning electron microscopy}

For the evaluation in scanning electron microscopy, the fragments fixed in glutaraldehyde solution buffered $2.5 \%$, were then post-fixed in osmium tetroxide $1 \%$ buffered sodium phosphate solution $\mathrm{pH} 7.4$ and $0.1 \mathrm{M}$, for $2 \mathrm{~h}$, followed by three washes in buffer and two immersion in distilled water. On completion of this step the fragments were treated with $1 \%$ tannic acid and dehydrated in increasing ethanol series $(50 \%$, 
$70 \%, 90 \%$ and $100 \%)$. After going through this stage, it was made the drying critical point apparatus using carbon dioxide and in sequence, finishing the amount sample holder (Stub) and the metal coating with gold by "sputtring" for observation in a scanning electron microscope (LEO VP® 435 - Carl-Zeis, Oberkochen, Germany) as the images having greater significance, electronically micrographed.

\section{RESULTS}

In conventional microscopy it could be seen that in group I (30 days), the lesions were mild to moderate, constituted by necrosis of the epithelial and mononuclear cell infiltrate distending the lamina propria, and inflammatory infiltrate consisting of macrophages, giant cells and macrophages epithelioid (Figure 1).

In group II (60 days), there was extensive ischemic necrosis area, characterized in denuding of epithelial cells, cell remains in the lumen surface and loss of intestinal crypts. Inflammatory infiltrate also occurred composed primarily of mononuclear cells in the lamina propria (Figure 2). The intestinal serosa was thickened by infiltrates of macrophages.

The group (90 days) the lesions were more evident. It was noted marked coagulative necrosis of epithelial cells and intestinal crypts (ischemic necrosis). There was infiltration of macrophages, lymphocytes and plasma cells and giant cells. Sometimes, there was loss of the intestinal epithelium, extensive fibrosis area in the submucosa and formation of granulomas foreign body and the presence of sutures in the granulomatous reaction, being observed marked thickening of the serous associated with infiltration of macrophages. Although there were extensive areas of inflammatory focus, causing distension of the submucosa to the muscular layer of the intestine (Figure 3).

The morphological changes observed in scanning electron microscopy in the different groups are arranged in Figure 4.

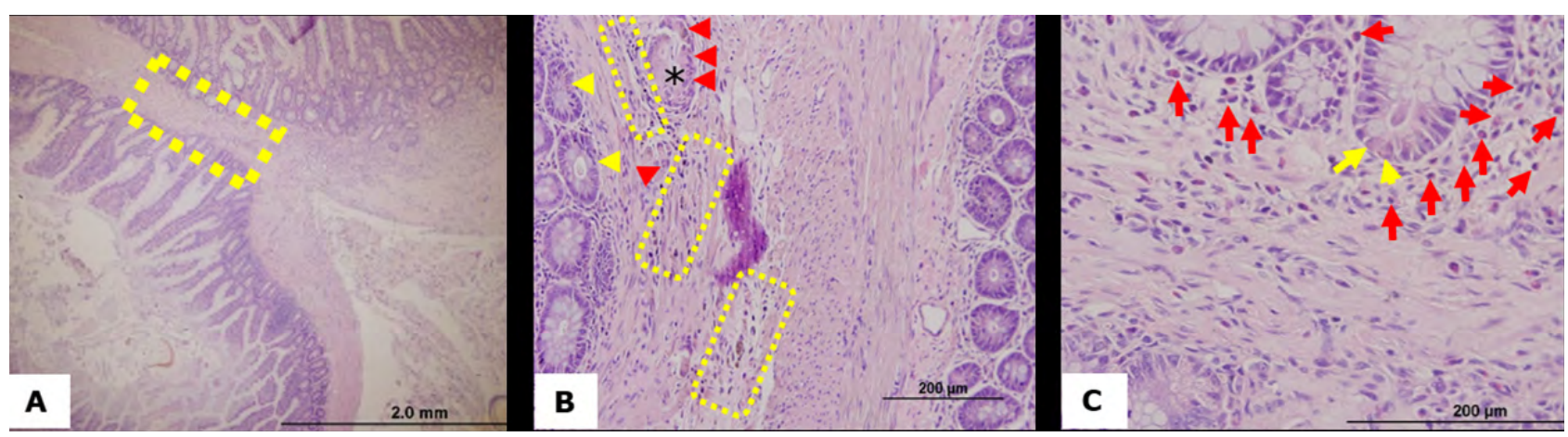

Figure 1. Photomicrograph of classical histopathology of Wistar rats submitted to induced bowel ligation, 30 days after surgical exposure. A: post-plication intestinal epithelial tissue (rectangle). B: Serous basal lamina and the intestine. It shows slight lesions, consisting of necrosis of the epithelium (head yellow arrow) and inflammatory infiltrate in the compounds serous mainly by macrophages (rectangle) and multinuclear giant cells (red arrowhead), the latter surrounding the foreign body (*). C: mononuclear infiltrate in serous and lamina propria (red arrow) and light necrosis of the epithelium (yellow arrow). [HE staining].
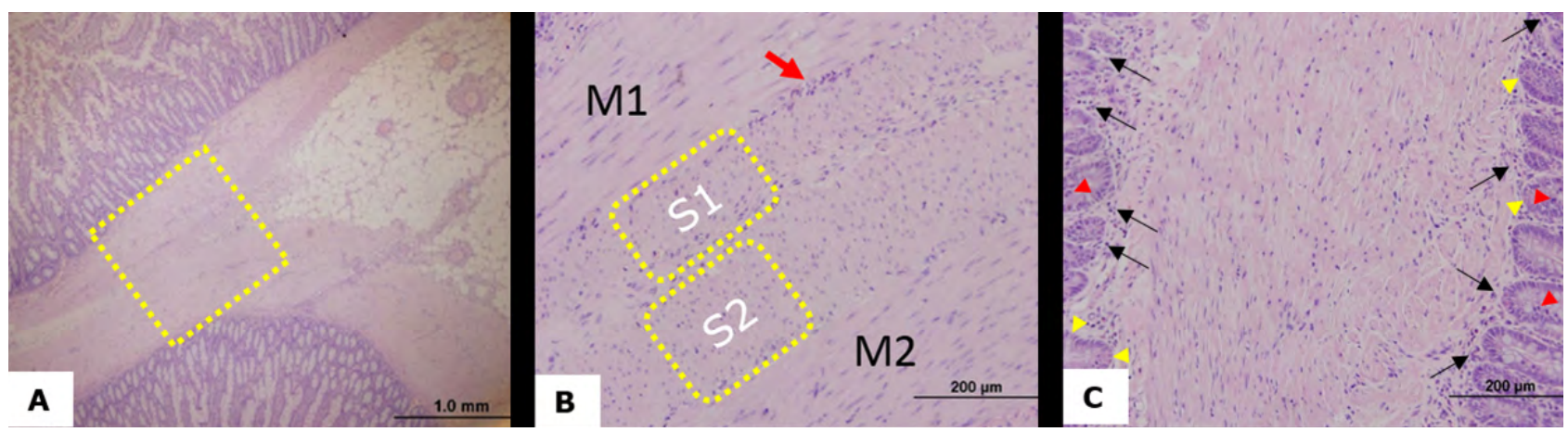

Figure 2. Photomicrography of classical histopathology of Wistar rats submitted to induced bowel ligation after 60 days of surgical exposure. A: grip region (square) between the intestinal epithelia. B: detail of hypertrophy of serous (S1 and S2) due to the increase in inflammatory infiltrate highlighted by the red arrow. The muscular layer is indicated as M1 and M2. C: infiltration of mononuclear cells in the lamina propria (black arrow) and necrosis of the epithelium due to cell death in the intestinal crypts (head yellow arrow) and necrotic debris present in the lumen (red arrowhead). [HE staining]. 


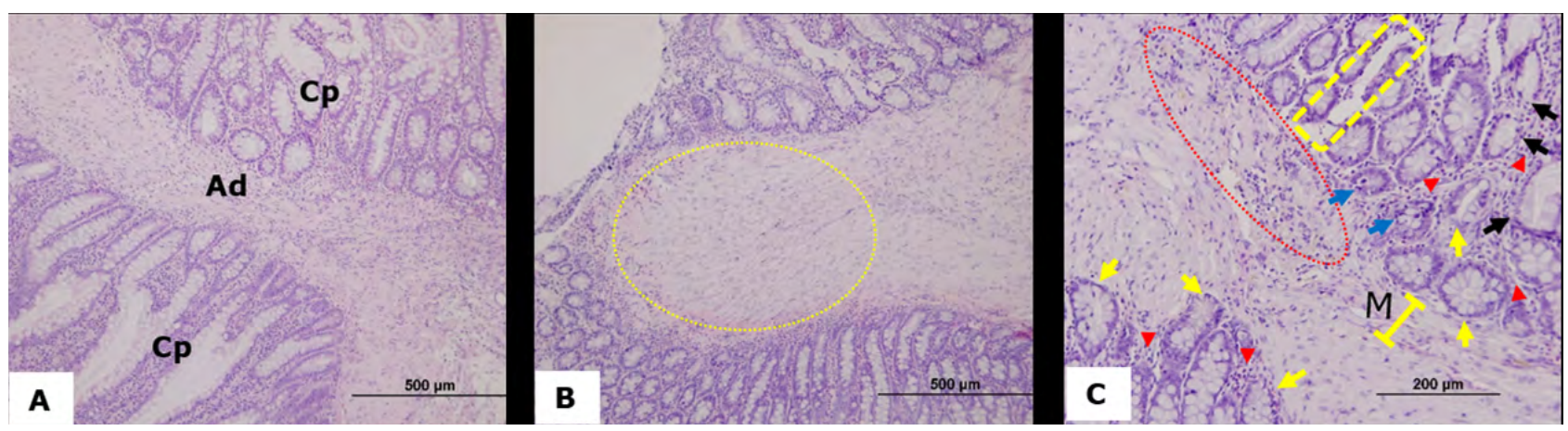

Figure 3. photomicrograph of classical histopathology of Wistar rats submitted to induced bowel ligation, 90 days after surgical exposure. A: crypts (Cp) and tissue adhesion area (Ad). B: Detail showing granuloma (yellow circle). C: inflammatory infiltrate in the submucosa (red circle) with distention of this layer to the muscle layer (M) in the intestine. It also shows the inflammatory infiltrate in the lamina propria circling the crypts (red arrowhead) and tissue necrosis evidenced by crypts dilated with squamous epithelium (blue arrow) within the crypts, due to cell death by ischemic necrosis and loss of epithelium (Rectangle ). [HE staining].

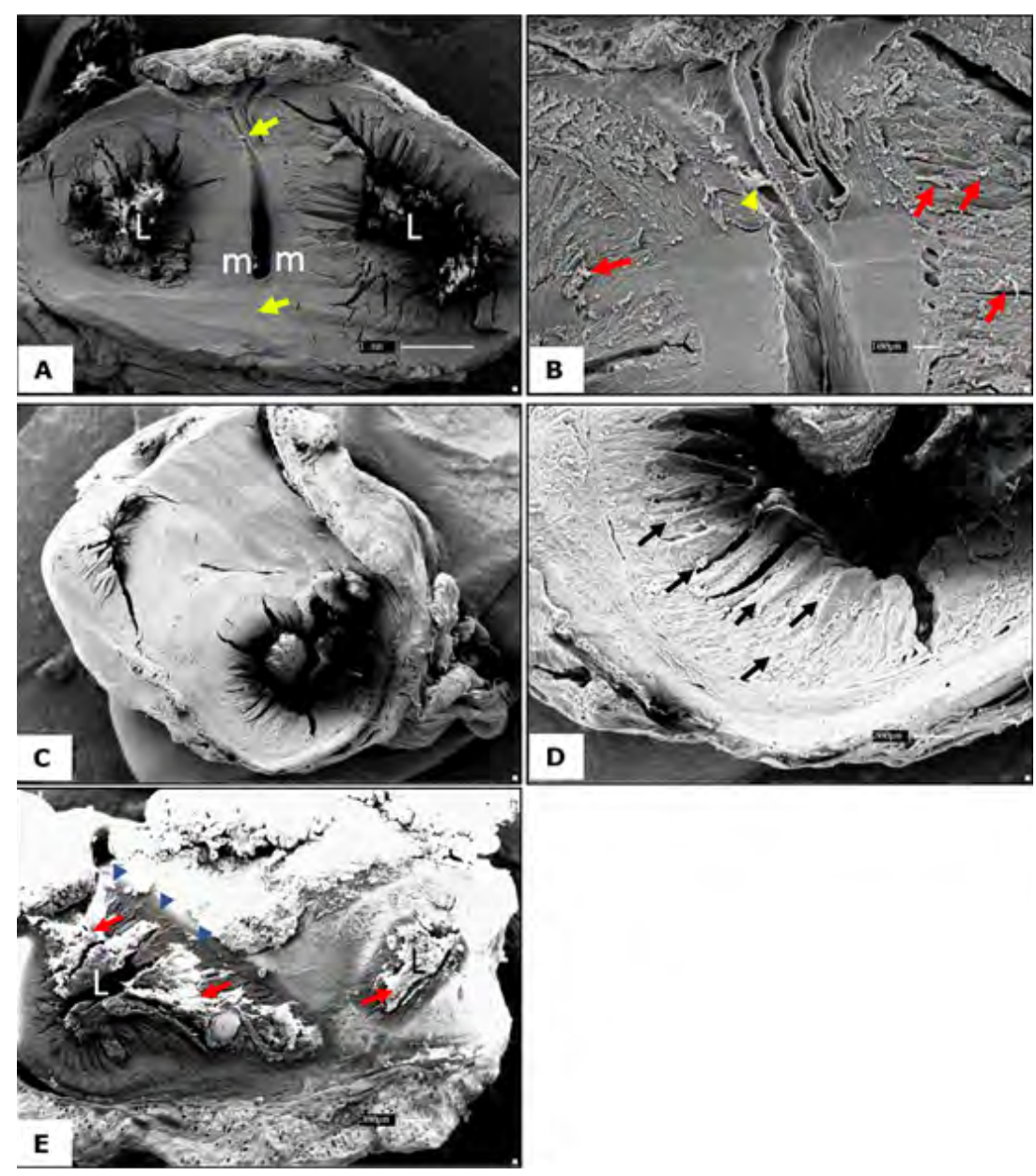

Figure 4. Wistar rats submitted to intestinal Eletrofotomicrografia ligation induced after surgical exposure. A: epithelium after 30 days of surgical exposure, which is evident beginning of the union of the two different intestinal walls (yellow arrow). B: intestinal epithelium at 30 days where we can see inflammatory infiltrate in serous (yellow arrow head) and basal lamina (red arrow). C: epithelium on the 60th postoperative day. There is almost complete adhesion of the two intestinal wall and stenosis of the lumen. D there is an increased inflammatory infiltrate in the lamina propria region. E: the epithelium disposal elapsed 90 days of enteropexy, where you can identify stenosis of the lumen (L) of the bowel, loss of epithelium (head blue arrow) and replacement by necrotic tissue whitish in color (red arrow). 


\section{DISCUSSION}

In the current study it was noticed microscopically that the groups had inflammatory reactions to foreign bodies. It is known that the sutures, independent of manufacture, behave as foreign bodies that induce tissue inflammation of the recipient organism and could harm the scar repair $[2,6]$. This reaction focal sutures starts with the trauma of passage of the needle and wire, but the response to the wire manifests as we know it, it manifests itself around the second and the seventh day after implantation $[14,15]$. The intensity of the reaction depends on several factors such as the nature of the wire used, the stitched surface area, the type and location of the tissue involved, in addition to the introduction of suture technique [2]. Thus, one of the likely causes of the inflammatory process observed in the test group, it was the piercing damage the tissue reaction of the needle along with the employee suture.

Among the surgical threads, the nylon type (which was chosen for the current experiment) is indicated in the approach tissues in general and bandages, including cardiovascular, ophthalmic and neurological procedures [11]. This category wire induces minimal inflammation of the receptor tissue [6]. Especially in the gastrointestinal tract during the exudative inflammatory phase of tissue recovery in general an appropriate suture may cause less injury and be found and of limited duration, keeping the tensile strength unchanged. In such aspects, the nonabsorbable suture has advantages over absorbable sutures, such as the lack of allergic side effects. However, the non-absorbable sutures, remain for longer periods in operated area, with the risk of causing a prolongation of inflammation and an increased possibility of infection. Thus, the ideal surgical thread is that which remains on the tissue, enough time for it to recover its required tension, causing an inflammatory response of short duration [3].

In studies of the histopathological analysis of the tissue reactions produced by the wire implant or nylon thread clamp in rats, it was observed that when the local action of two implants were compared, inflammation showed qualitatively similar responses, although they had different characteristics regarding their course. Animals implanted with the wire initially showed acute and chronic reaction remedial order. However, the group receiving the clamp implant at first reacted with a chronic-active and ceasing reaction with a reparative process character [5]. Such inflammatory reaction was similar found by other researchers [14] when they compared the thread of nylon and wire poliglecaprone 25, on internal and external sutures and observed that external sutures done with nylon produce less tissue reactivity, while the sutures internal, this yarn showed a greater tissue reaction, which declined over the postoperative time. The nylon thread causes an inflammatory reaction of small extent and for a limited time and in the deep sutures cause foreign body reactions [14]. Thus, due to the characteristics of the material and the fact that monofilament nylon has advantages in terms of fluid absorption and wicking in addition to a low coefficient of friction, then reiterating the correct choice of the suture in the current study. The biocompatibility of the suture is a very important information in order to know the biological response to the material, especially so that it can be indicated in situations where there is risk of injury during the healing process [15].

Inflammation is proportional to the proliferation of fibroblasts and the presence of fibrous tissue around the suture [11]. This quote confirms the analyzed samples, in which, in all postoperative times showed inflammatory process, although at different magnitudes.

Surgical research in laboratory animals has expanded in recent decades, mainly due to better anesthetic support, the sophistication of infrastructure, material for perioperative continuous monitoring and an incessant search for species that reproduce human morbid conditions. The main focus of these studies have been improving the knowledge about the pathophysiological mechanisms of disease, undertake therapeutic trials with new drugs, studying biomarkers and evaluate new techniques to be applied prospects in man [16]. The rat (Rattus norvegicus) Wistar is considered an animal model suitable for various surgical procedures, including the small intestine transplant since they are more resistant to infection, besides being small, having low cost and evidence fast response to inflammatory processes which are favorable factors in the framework of academic research [16,20]. The references cited above justified the predilection for experimental prototype of the described work.

The most common sites of occurrence of intestinal are ileocolic intussusception junction and jejunojejunal segment [10]. In a study of 20 cats that 
had intussusception it was found that eight of the affected cats expressed in disease jejunojejunal region [4]. So it was based on the design in evidence in implementing the enteropexy procedure in jejunal segment, making the closest simulation of the clinical reality and thus leading to verification of the morphological consequences of surgical resolution.

The enteroplicatura has been used to reduce the occurrence of intussusception, promoting the adhesion of the adjacent serosa layers of intestinal segments and thereby decreasing intestinal motility, their applicability is reported in humans, dogs and cats $[9,12,17]$. However, they are described on the technical complications as fistula formation and partial bowel obstruction [12]. In this test, visualization by electron microscopy, stenosis in the segments analyzed was explained by the intestine is a tubular body with relatively narrow lumen and the presence of the healing process. However, a possible surgical suture fragment penetration of the intestinal mucosa could also relate to luminal narrowing.

\section{CONCLUSION}

The enteropexy technique causes morphological changes in intestinal epithelium of rats, evidenced in conventional and electron microscopy, progress with the passing of time the procedure.

Declaration of interest. The authors report no conflicts of interest. The authors alone are responsible for the content and writing of the paper.

\section{REFERENCES}

1 Akinrinmade J.F. \& Lawal A.O. 2010. Gross and histologic evaluation of abdominal adhesions associated with chromic catgut and polypropylene sutured enteropexies in dog. International Journal of Morphology. 28(4): 1221-1225.

2 Barros M., Gorgal R., Machado A.P., Correia A. \& Montenegro N. 2011. Princípios básicos em cirurgia: fios de sutura. Acta Medica Portuguesa. (24): 1051-1056.

3 Bernis-Filho W.O., Wouters F., Wouters A.A., Bernis V.M., Lopes L.R. \& Andreollo N.A. 2013. Comparative study of cotton, polyglactin and polyglecaprone sutures in intestinal anastomoses in dogs. Arquivos Brasileiros de Cirurgia Digestiva. 26(1): 18-26.

4 Burkitt J.M., Drobatz K.J., Saunders H.M. \& Washabau R.J. 2009. Signalment, history, and outcome of cats with gastrointestinal tract intussusception: cases (1986-2000). Journal of the American Veterinary Medical Association. 234(6): 771-776.

5 Costa Neto J.M., Lima A.E.S., Oriá A.P., Martins Filho E.F. \& Teixeira D.M. 2014. Análise histopatologica das reações teciduais produzidas pelo implante de fio e de braçadeira de náilon. Enciclopédia Biosfera, Centro Científico Conhecer. 10 (18): 291-298.

6 De Souza L.A., Freitas P.M.C., Dias T.A., Eurides D., Beretta D.C., Fares N.B., Silva T.M. \& Mota F.C.D. 2014. Enterorrhaphies in rabbits with extramucous inverted suture versus single continuous contaminant suturing and cushing: macroscopic evaluation. PUBVET. 8(17): 1-10.

7 Fossum T.W. \& Hedlund C.S. 2003. Gastric and intestinal surgery. Veterinary Clinics of North America: Small Animal Practice. 33(5): 1117-1145.

8 Kim S.J., Park C.H., Kim Y.M., Kim S.Y., Chun S.Y., Kwon C.W., Park J.W., Kim K.O., Baek I.H., Yoo K.S. \& Kim J.H. 2012. A clinical review of the intussusception in adult. Intestinal Research. 10(2): 183-188.

9 Levitt L. \& Bauer M.S. 1992. Intussusception in dogs and cats: A review of 36 cases. The Canadian Veterinary Journal 33(10): 660-664.

10 Lukanc B., Pogorevc E., Kastelic A. \& Erjavec V. 2014. Retrograde jejunal intussusception in one year old cat after treatment with metoclopramide and menbutone. Slovenian Veterinary Research. 51(4): 201-207.

11 Mota J.C.N., Queiroz A.C.D., Araújo R.P.C.D., Pinto A.S., Sousa G.G. \& Pinto M.D.G.F. 2010. Aspectos anatomohistológicos da sutura na língua com poliglecaprone 25, náilon e categute simples em ratas. Revista de Ciências Médicas e Biológicas. 8(2): 124-131.

12 Nash J.M. \& Bellenger C.R. 1998. Enteroplication in cats, using suture of N-butyl cyanocrylate adhesive. Research in veterinary science. $65(3):$ 253-258.

13 Oakes M.G., Lewis D.D., Hosgood G. \& Beale B.S. 1994. Enteroplication for the prevention of recurrent intussusceptions in dogs: 31 cases (1978-1992). Journal of the American Veterinary Medical Association. 205(1): 72-75. 
14 Ribeiro C.M., Silva Júnior V.A., Silva Neto J.C. \& Vasconcelos B.C. 2005. Clinical and histopathological study of tissue reactivity to monofilament suture materials: nylon and poliglecaprone 25 in rats. Acta Cirurgica Brasileira. 20(4): 284-291.

15 Saito C.T.M.H., Bernabé P.F.E., Okamoto R. \& Okamoto T. 2006. Reação do tecido conjuntivo subcutâneo de ratos aos fios de sutura poliglecaprone 25 (monocryl) e poliglactina 910 (vicryl). Revista Salusvita. (26): 27-38.

16 Schanaide A. \& Silva P.C. 2004. Uso de animais em cirurgia experimental. Acta Cirúrgica Brasileira. $19(4)$ : $441-447$.

17 Sivasankar M. 2000. Recurrent intussusception in a 14-month-old, spayed, female German shepherd cross. The Canadian Veterinary Journal. 41(5): 407-408.

18 Slatter P. 2003. Textbook of small animal surgery. 3rd edn. Philadelphia: Saunders, 1420p.

19 Tolosa E.M.C., Bermer O.A. \& Freitas-Neto A.G. 2003. Manual de Técnicas para Histologia Normal e Patológica. 2.ed. São Paulo: Manole, 241p.

20 Waisberg D.R., Galvão R.C., Galvão F.H.F. \& D’Albuquerque L.A.C. 2009. Transplante intestinal em ratos utilizando nova técnica de microanastomose sem sutura com cola e molde tubular (Cuff-Glue). Revista de Medicina. 88(3/4): 207-218. 